\title{
ANTERIOR INTERHEMISPHERIC APPROACH IN CRANIOPHARYNGIOMAS : PERSONAL EXPERIENCE OF OPERATIVE TECHNIQUE AND RESULTS
}

\author{
Jaideep Chandra ${ }^{1}$, Santosh Shah $^{2}$
}

ABSTRACT

\section{INTRODUCTION}

Removal of intracranial supra-sellar masses continues to be a surgical challenge. Various approaches have been used by different authors with varying results. Anterior basal interhemispheric approach is most suitable with better results than other approaches for craniopharyngiomas.

\section{MATERIAL AND METHODS}

Fifteen patients with large craniopharyngiomas having third ventricular and or retro or supra-sellar extensions or reaching the interpeduncular cisterns were operated by this approach, over a period of seven years since the first use of this approach at our institute. The data of patients opearated by this approach were then retrospectively analysed. There were eleven males and four females with five patients in the pediatric age group. Follow up range was from 2 to 83 months with a mean of 21.6 months.

\section{RESULTS}

Total excision was achieved in seven (46.6\%) and near total excision in another seven (46.6\%), partial excision was done in only one $(6.66 \%)$. Seven patients with total excision were disease free at mean follow up of 6.8 months. There was asymptomatic recurrence in two (13.33\%) patient with near total excision at 11 and 63 months respectively and were given radiotherapy post-operatively. All patients were symptom free except one with diabetes insipidus (DI) and one mortality, and one with post operative visual deterioration.

\section{CONCLUSION}

Anterior basal interhemispheric approach is a useful alternative to other transcranial approaches in the management of the craniopharyngiomas. It has the advantage of being a midline approach and displays the tumour brain interface better.

KEYWORDS Intracranial, transcranial, craniopharyngiomas

1. Department of Surgery (Neurosurgery), Universal College of Medical Sciences, Bhairahawa, Nepal

2. Department of Surgery (CTVS), Universal College of Medical Sciences, Bhairahawa, Nepal

DOI: https://doi.org/10.3126/jucms.v6i2.22468

For Correspondence
Dr. Jaideep Chandra
Neurosurgery Unit
Department of Surgery
Universal College of Medical Sciences
Bhairahawa, Nepal
Email: jaideep999@gmail.com




\section{INTRODUCTION}

Craniopharyngiomas can be attacked by various surgical routes, pterional, subfrontal, transcallosal-transventricular, transcortical-transventricular, transtemporal, subtemporal and trans-sphenoidal routes. ${ }^{1,2}$

Bifrontal basal interhemispheric approach has been found to be useful by many authors in resecting large third ventricular tumours with retrosellar and suprasellar extensions. ${ }^{2}$ The advantage is that it allows direct visualization of the anterior circle of Willis and the perforators. The inferomedial angle of the optic nerves can be directly decompressed. ${ }^{3}$ The lamina terminalis, midline of the hypothalamus, interpeduncular cisterns can be easily visualized; if necessary the anterior communicating artery (ACOM) can be divided to improve the lateral tumour exposure without neurological sequelae. We present our experience with this approach.

\section{MATERIAL AND METHODS}

Fifteen patients with large craniopharyngiomas having third ventricular and/or retro or supra-sellar extensions or reaching the inter-peduncular cisterns were operated by this approach, over a period of seven years since the first use of this approach at our institute. The data for patients opearated by this approach were then retrospectively analysed. There were eleven males and four females with five patients in the pediatric age group. Follow up range was from 2 to 83 months with a mean of 21.6 months.

The presentation, surgery and outcome were evaluated for each with emphasis on olfaction and vision. Endocrinological profile was done with thyroid stimulating hormone(TSH) in all, growth hormone $(\mathrm{GH})$ in children, follicular stimulating hormone (FSH), luteinising hormone $(\mathrm{LH})$ and prolactin $(\mathrm{Prl})$ in clinically involved were done. All patients had contrast CT scans, and five also had contrast MRI scans done preoperatively. Post-operative CT scans were done at 6 weeks to see the extent of tumour removal. Endocrinological profiling was also repeated at 6 weeks. Subsequently, they were followed at 3 months, and then at 6 monthly intervals. Visual, endocrinological and radiological evaluations were done. Angiography was not performed in any case.

\section{RESULTS}

Total excision was achieved in seven $(46.6 \%)$ and near total excision in another seven (46.6\%), partial excision was done in only one $(6.66 \%)$. The seven patients with total excision were disease free at mean follow up of 6.8 months. Out of the patients with near total excision, there was asymptomatic recurrence in two (13.33\%) at 11 and 63 months respectively. The patient with partial excision were given radiotherapy post-operatively. Two patients with stable disease and asymptomatic recurrence non enlarging tumours were followed without radiotherapy. All patients were symptom free except one with diabetes insipidus (DI) and one mortality, and one with post operative visual deterioration.

Vision improved in nine out of ten patients (90\%). Two patients were completely blind prior to surgery and three had normal vision in pre-op. Fields of vision improved in all three patients where it was possible to chart it before surgery, in others due to altered sensorium or extreme young age it could not be charted. Deterioration of normal vision occurred in one and in other there was no improvement in vision after surgery $(6.66 \%)$. Smell was preserved in eight $(53.3 \%)$ patients on both sides lost in four $(26.6 \%)$ and not recorded in three $(20 \%)$. Hypothalamic and frontal lobe symptoms improved in all patients. Only one had permanent DI. Endocrinopathy improved in two (13.3\%), hyperprolactin-aemia in one and hypothyroidism in another. Results are shown in Table 1.

\section{Table 1. Showing findings post-surgery}

\begin{tabular}{|l|l|l|}
\hline \multicolumn{1}{|c|}{ Outcomes } & Number & Percentage \\
\hline Vision Improved & $9 / 10$ & 90 \\
\hline Field of Vision Improved & $3 / 3$ & 100 \\
\hline Deterioration of Vision/No Improvement & $1 / 1$ & 6.67 each \\
\hline Olfaction Preserved & 8 & 53.3 \\
\hline Olfaction Lost & 4 & 26 \\
\hline Hypothalamic Symptoms Improved & $3 / 3$ & 100 \\
\hline Frontal Lobe Symptoms & $3 / 3$ & 100 \\
\hline Endocrinopathy Improved & $2 / 3$ & 66.67 \\
\hline Permanent Diabetes Insipidus & 1 & 6.67 \\
\hline Mortality & 1 & 6.67 \\
\hline
\end{tabular}

\section{DISCUSSION}

Management of craniopharyngiomas remains a complex and baffling problem to neurosurgeons as commented by Harvey Cushing at the start of the $20^{\text {th }}$ century and it remains so till date. However, with the use of MRI and the application of the knowledge of micro-neuroanatomy, the implementation of micro-neurosurgical techniques, and the use of hormone replacement there has been a significant improvement in the outcome of these patients. Most commonly used approaches are pterional or sub-frontal using the inter-optic or caroticooptic and the lamina terminalis routes to decompress the tumours. $^{4-6}$ Though the pterional approach provides the shortest route, it has certain limitations: in a prefixed chiasma the inter-optic space is not available. The carotico-optic space provides a very narrow corridor for working between vessels and the retro-sellar area falls in a blind spot, requiring traction to pull the tumour into view risking damage to vital neural structures. Maria et al has recently described the difficulties encountered with this approach. ${ }^{7}$ This lead many neurosurgeons to use the anterior basal interhemispheric 
approach for large tumours with retro and supra-sellar extensions. ${ }^{8-10}$ The advantage being minimum retraction of the frontal lobes and midline orientation to the lamina terminalisand the hypothalamus and the complete visualisation of the anterior circle of Wilis and the visual apparatus including both the optic tracts. The inferio-medial angles of both optic nerves can be seen and dealt with at the same time. The sella can be dealt with by drilling the planum sphenoidale, if needed. ${ }^{10}$ The supra-sellar and retro-sellar portions can be removed under direct vision. ${ }^{2}$ If needed, the ACOM can be divided to access the lateral extent of the tumour. ${ }^{11}$ Tumours of the third ventricle can also can be safely removed by this approach. Tetsuo Kanno et $\mathrm{al}^{12}$ reported a subcortical haematoma due to coagulation of bridging veins which was not seen in our cases as we preserved them.

Comparison of results between various approaches is difficult as the experience and personal preference of the neurosurgeon largely dictates the selection of approach. Fahlbusch et al have shown better total tumour removal rates with this approach $(59 \%)$ than with pterional approach $(50 \%)$ and prefer to use this approach for tumours with large supra and retro-sellar extensions. $^{2}$

J Srinivasan has advocated removal of the orbital rims for this approach but since this approach is essentially midline and over the cribriform plates, the removal of the rims is unlikely to be of added advantage. ${ }^{13} \mathrm{M}$ Shibuya et al recommends this approach in all cases of craniopharyngiomas and has a total or near total excision in all of his twenty two cases without any mortality. ${ }^{9}$ In our present series total or near total excision was achieved in fourteen out of fifteen cases.

Various authors Yasargil ${ }^{14}$ Hoffman $^{4}$ and L Symon ${ }^{6}$ are of the opinion that the best results are achieved with initial complete excision, but this can only be achieved at the cost of high mortality and morbidity since some tumours have dense adhesions to vital neural structures. ${ }^{1,2}$

We followed the principle of Fahlbusch ${ }^{2}$ in attempting complete excision but not hesitating to leave a small portion of the capsule if it was densely adherent to vital neural or vascular structures. With this a total or near total excision was achieved in fourteen out of fifteen cases (93.3\%). Biological behaviour of the tumours is variable and some do not grow after subtotal excision. ${ }^{9}$ Fahlbusch reserves radiotherapy for subtotally resected tumours only if they show signs of regrowth. ${ }^{2}$ We have also followed this approach. Out of four recurrences in our series two were irradiated and two were followed without further interventions.

Our smell preservation rate was eight out of fifteen (53.3\%), which was lower than that of Fujiwara ${ }^{3}$ and Sepehrnia. ${ }^{8}$ They have used this approach in aneurysms and other lesions of the anterior cranial fossa. J Srinivasan ${ }^{13}$ mentions anatomical preservation of olfactory tracts in 10/14 cases but does not mention anything about smell preservation. We preserved the tracts anatomically in fourteen out of fifteen cases. Vision improved in nine out of ten of our cases $(90 \%)$. Fahlbusch et al reported a $71 \%$ improvement and a $30 \%$ normalisation of vision. Deterioration occurred in $6.6 \%$ of our case as opposed to $20 \%$ reported by Fahlbusch ${ }^{2}$ and $14.6 \%$ by all approaches combined. J Srinivasan ${ }^{13}$ et al reported an improvement in $64.3 \%$, no change in $28.5 \%$, and a deterioration in $7.1 \%$, while Shibuya et $\mathrm{ll}^{9}$ reported a $59 \%$ improvement, no change in $32 \%$ and deterioration in $9 \%$. In three of our cases, vision did not improve but two were already completely blind before surgery. Deterioration of vision has been reported in $1.3-36 \%$ in various series. ${ }^{15}$ Hoffman et al advocating aggressive total excision have produced 28 percent visual deterioration. ${ }^{5}$ Baskin et al advocates subtotal excision with radiotherapy and achieved vision improvement in $93 \%$ and deterioration in only $2 \%$ of his cases. ${ }^{1}$ Cavazutti et al using subfrontal approach had vision detioration in $10 \%$ of his cases. ${ }^{16}$ The cause of deterioration in vision is traction on the visual apparatus or damage to its micro vascular supply.In our series, additional morbidity was transient CSF rhinorrhea in one and an EDH in one. The commonest morbidity reported in various series are vision deterioration or DI or endocrinopathy.

Fahlbusch reported a morbidity of $12.8 \%$ and Hoffman in his two series had morbidity rates of $56 \%$ and $52 \%$. ${ }^{4,5}$ Baskin et al had a $23 \%$ rate of DI and overall morbidity rate of $12 \% .{ }^{1} \mathrm{~L}$ Symon had a morbidity rate of $22.2 \%{ }^{6}$ Yasargil had mortality and morbidity rates of $16 \%$ and $16.7 \%$ respectively. ${ }^{14}$ We had a mortality of $6.6 \%$ and the mortality in other series is as follows: Fahlbusch-2.1\%, ${ }^{2}$ Cavazutti- $11.5 \%,{ }^{16}$ Hoffman- $2 \%{ }^{4}$, Baskin-2.7\% ${ }^{1}$ and L Symon-5\%. ${ }^{6}$ However, none of the mortalities are related to the approach.

Anterior interhemispheric approach provides a better chance of complete tumour removal with lesser mortality and morbidity.

\section{CONCLUSION}

In conclusion, we would say that anterior basal interhemispheric approach is a useful alternative to other transcranial approaches in the management of the craniopharyngiomas. It has the advantage of being a midline approach and displays the tumour brain interface better. It is especially useful for high supra- or retro-sellar extensions and inter third ventricular tumours. It provides a better chance at tumour removal with lesser risk of hypothalamic and other neural and vascular injuries. 


\section{REFRENCES}

1. Baskin DS, Wilson CB. Surgical management of craniopharyngiomas: a review of 74 cases. Journal of neurosurgery. $1986 \mathrm{Jul} ; 65(1): 22-7$.

2. Fahlbusch R, Honegger J, Paulus W, Huk W, Buchfelder M. Surgical treatment of craniopharyngiomas: experience with 168 patients. Journal of neurosurgery. 1999 Feb;90(2):237-50.

3. Fujiwara H, Yasui N, Nathal-Vera E, Suzuki A. Anosmia after anterior communicating artery aneurysm surgery: comparison between the anterior interhemispheric and basal interhemispheric approaches. Neurosurgery. 1996 Feb 1;38(2):325-8.

4. Hoffman HJ, Silva MD, Humphreys RP, Drake JM, Smith ML, Blaser SI. Aggressive surgical management of craniopharyngiomas in children. Journal of neurosurgery. 1992 Jan;76(1):47-52.

5. Hoffman HJ, Hendrick EB, Humphreys RP, Buncic JR, Armstrong DL, Jenkin RD. Management of craniopharyngioma in children. Journal of neurosurgery. 1977 Aug;47(2):218-27.

6. Symon L, Sprich W. Radical excision of craniopharyngioma: Results in 20 patients. Journal of neurosurgery. 1985 Feb;62(2) :174-81.

7. Maira G, Anile C, Colosimo C, Cabezas D. Craniopharyngiomas of the third ventricle: trans-lamina terminalis approach Neurosurgery. 2000 Oct 1;47(4):857-65.

8. Sepehrnia A, Knopp U. Preservation of the olfactory tract in bifrontal craniotomy for various lesions of the anterior cranial fossa. Neurosurgery. 1999 Jan 1;44(1):113-7.

9. Shibuya M, Takayasu M, Suzuki Y, Saito K, Sugita K. Bifrontal basal interhemispheric approach to craniopharyngioma resection with or without division of the anterior communicating artery. Journal of neurosurgery. 1996 Jun;84(6):951-6.

10. Peter W. Carmel: Craniopharyngiomas in Neurosurgery: Wilkins and Rengachary, McGraw Hill, 1996 Vol.1,1389-1400.

11. Majjid Saamii: Surgical management of craniopharyngiomas: Operative Neurosurgical Techniques: Indication Methods Results Edition 4; Henry Schmidek, William Sweet, W.B. Saunders, 2000 Vol. $1489-502$.

12. Tetsuo Kanno, Atsushi Kasania, Motoi Shoda, Chikashi Yamaguchi, Youko Kato: A pitfall in interhemispheric translamina terminalis approach for the removal of a craniopharyngioma: Significance of preserving the draining veins. Part 1 Clinical Study. Surgical Neurology 1989:32:111115.

13. Srinivasan Jayshree, Andrew T. Dailey, Mitchel S. Berger: Bifrontal olfactory nerve-sparing approach to lesions of the suprasellar region in children. Paediatric Neurosurgery, 1999;30:245-252.
14. Yașargil MG, Curcic M, Kis M, Siegenthaler G, Teddy PJ, Roth P. Total removal of craniopharyngiomas: approaches and longterm results in 144 patients. Journal of neurosurgery. 1990 Jul;73(1):3-11.

15. Michael L.J. Apuzzo: Craniopharygiomas in brain surgery: complications avoidance and management. Churchil Living stone, 1993, Vol.1, 313-378.

16. Cavazzuti V, Fischer EG, Welch K, Belli JA, Winston KR. Neurological and psychophysiological sequelae following different treatments of craniopharyngioma in children. Journal of neurosurgery. $1983 \mathrm{Sep} ; 59(3): 409-17$. 